\title{
An Unstructured Phylogeographic Pattern with Extensive Gene Flow in an Endemic Bird of South China: Collared Finchbill (Spizixos semitorques)
}

Bin Gao ${ }^{1,2}$, Lijiang Yu ${ }^{3}$, Yanhua Qu ${ }^{1}$, Gang Song ${ }^{1}$, Chuanyin Dai ${ }^{1}$, Ruiying Zhang ${ }^{1}$, Zuohua Yin ${ }^{1}$, Kaifeng Wang ${ }^{4}$, Xuebin Gao ${ }^{4}$, Shou-Hsien $\mathrm{Li}^{5}$ and Fumin Lei ${ }^{1, *}$

1 Key Laboratory of Zoological Systematics and Evolution, Institute of Zoology, Chinese Academy of Sciences, Beijing 100101, China; E-Mails: quyh@ioz.ac.cn (Y.Q.); songgang@ioz.ac.cn (G.S.); daicy@ioz.ac.cn (C.D.); zhangry@ioz.ac.cn (R.Z.); yinzh@ioz.ac.cn (Z.Y.)

2 Graduate University of the Chinese Academy of Sciences, Beijing 100049, China;

E-Mail: rahello1234@163.com (B.G.)

3 Shanghai Science \& Technology Museum, Shanghai 200127, China;

E-Mail: yulj1709@126.com (L.Y.)

4 Shaanxi Institute of Zoology, Xi'an 710032, China; E-Mails: wangkf@ms.xab.ac.cn (K.W.); gaoxb63@163.com (X.G.)

5 Department of Life Science, National Taiwan Normal University, Taipei 116, Taiwan;

E-Mail: t43028@ntnu.edu.tw (S.H.L.)

* Author to whom correspondence should be addressed; E-Mail: leifm @ioz.ac.cn; Tel.: +86-10-648-07159; Fax: +86-10-648-07159.

Received: 30 March 2011; in revised form: 24 May 2011 / Accepted: 3 June 2011 / Published: 7 June 2011

\footnotetext{
Abstract: Recent phylogeographical studies indicated that glacial oscillations played a key role on the phylogeographic pattern of extant species. As most studies have previously been carried out on heavily ice-covered regions, such as in European and North American regions, potential effects of climatic oscillations on species that are distributed on ice-free regions are less known. To address this, we investigated the phylogeographic pattern of an avian species endemic to South China, which was not glaciated during the Pleistocene glaciations. By using 2142 bp mitochondrial DNA, we identified 89 haplotypes defined by 39 polymorphic sites. A combination of high haplotype diversity (0.786-1.00) and low nucleotide diversity $(0.00132-0.00252)$ was detected among geographic populations. Explicit genetic divergence was observed between $S$. s. semitorques and $S$. s. cinereicapillus
} 
but not detected among geographic populations of $S$. s. semitorques. Divergence time of the two subspecies was dated back to $87 \mathrm{Kyr}$ which is congruent with the interglacial MIS 5. A weak phylogeographic structure due to strong gene flow among geographic populations was identified in this species, suggesting complex topography of South China has not formed barriers for this species.

Keywords: Collared Finchbill; East Asia; unglaciated region; phylogeography

\section{Introduction}

It is widely accepted that glacial oscillations during Pleistocene shaped the geographic distribution and genetic pattern of many plant and animal species on previously glaciated regions [1-3]. For species distributed in Europe and North America, their phylogeographic studies have shown congruent patterns. During glacial advance, these species receded to southern refugia. As ice sheets retracted, they experienced rapid expansions and recolonized northern latitudes after the Last Glacial Maximum (LGM) [3-5]. The repeated range expansions and retractions have considerably influenced their genetic diversity and population differentiations.

In contrast, the influence of recent climatic oscillations due to glacial cycles on the phylogeographic patterns of species in unglaciated regions, especially in East Asia, remain poorly understood [3,6,7]. Recently, comparative phylogeographic research in an unglaciated North American region has shown congruent isolated and differentiation patterns with those of species distributed on previously glaciated areas, despite the fact that in some cases they may be older (Pliocene) [8].

East Asia harbors one of the most diverse temperate fauna as it was never heavily covered by ice-sheets $[9,10]$. During Pleistocene, East Asia was a mosaic of mountains lower than $2000 \mathrm{~m}$ and characterized by a relatively mild Pleistocene climate [11-14]. The climatic stability and heterogeneous topology of this region potentially hosted microclimatic zones capable of supporting a variety of habitats over time [15]. Three previous avian studies of this region showed different evolutionary history compared with Europe and North America [14,16,17]. Thus, glacial refugia may have been available for East Asian species throughout their entire ranges, instead of being limited to several regions of Europe and North America [14]. Accordingly, we assume that the milder Pleistocene climate may have evoked less stress for East Asian species than European and North American species, and possibly these species have similar patterns.

To address this, we used two fragments of mitochondrial DNA to study the phylogeographical structure of a passerine species, the Collared Finchbill (Spizixos semitorques). The Collared Finchbill is endemic to south China, with two described subspecies: S. s. semitorques and S. s. cinereicapillus. S. s. semitorques cover a large area of South Mainland China, while S. s. cinereicapillus is only found in Taiwan. The Collared Finchbill distributes mainly in shrubbery, bamboo forests, and grassy areas on hilly and flat terrain below $1000 \mathrm{~m}$, and its distribution is roughly between $20^{\circ} \mathrm{N}$ and $30^{\circ} \mathrm{N}$ in latitude, and $105^{\circ} \mathrm{E}$ and $120^{\circ} \mathrm{E}$ in longitude [18]. Understanding the genetic variation among populations and the past demographic processes sculpting the current population structure of S. semitorques might enrich 
our understandings about the role of climatic changes during the Pleistocene glaciations on the phylogeographical formation of birds endemic to South China.

\section{Results and Discussion}

\subsection{Results}

A combined length of 2142 bp mitochondrial genome, including Cytb (977 bp) and partial control region and tRNA-Glu (1165 bp) was obtained. Sequences aligned unambiguously have no gaps and there were no nonsense codons in protein-coding regions. Sixty-nine variable sites define 89 haplotypes. Most haplotypes are singletons, while there are only a few common haplotypes (10 see Attachment 1) shared by several geographical populations (Figure 1). The haplotype network depicts a compact topology and indicates no phylogeographic structure.

Figure 1. Haplotypes median-joining network for Collared Finchbill generated by NETWORK 4.6.
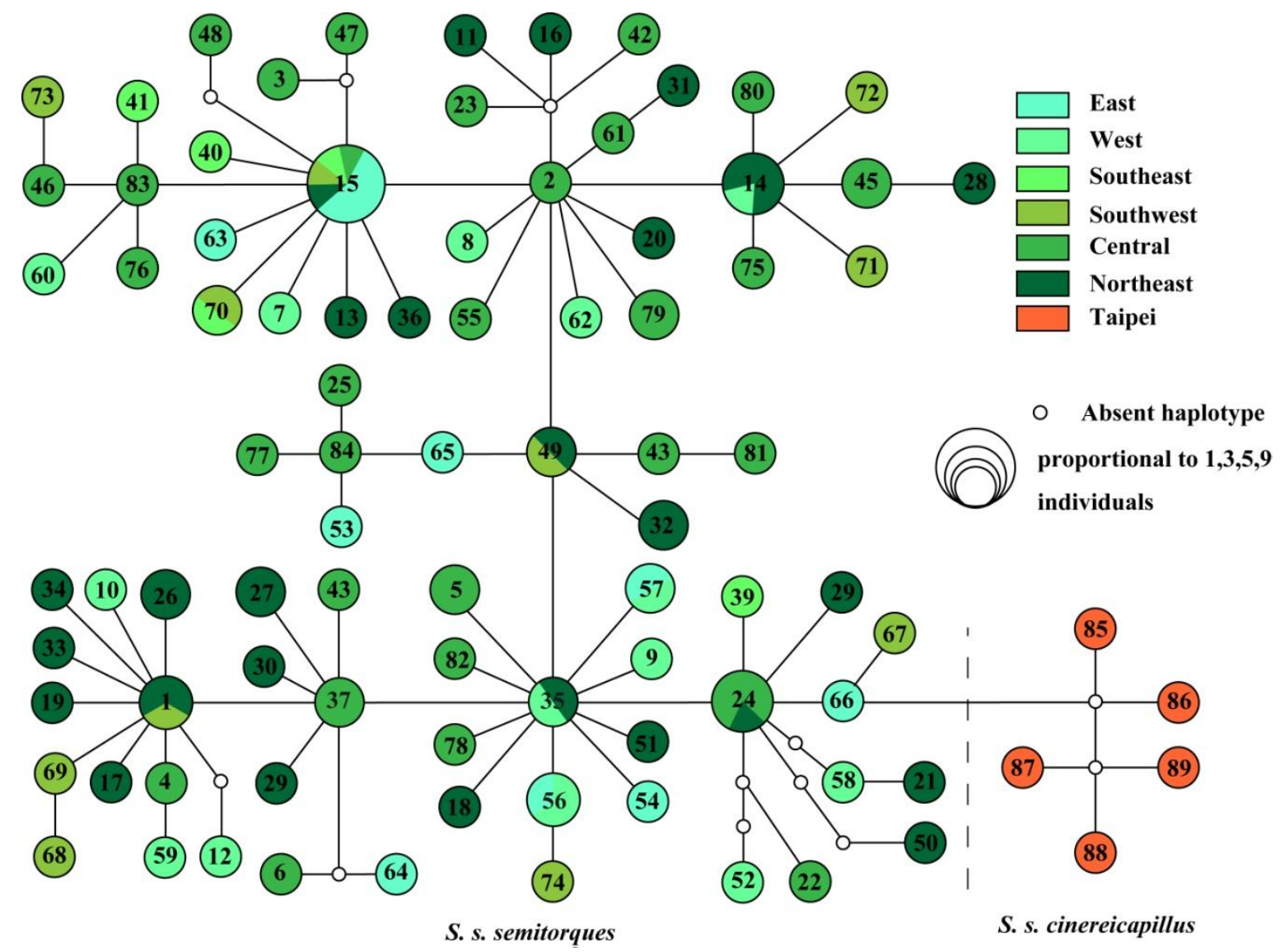

Neutrality test was conducted on geographic populations which contained at least five individuals. Tajima's $D$ values detected negative values for all populations, but none are significant (Table 1). Fu's Fs statistics revealed significant negative values for SXFP $(0.00)$ and GSWX $(<0.01)$ populations. Fu and Li's $D$ tests showed negative values for SXFP $(<0.05)$, HNYJ $(<0.01)$ and GZGD $(<0.01)$ populations. No population showed significant negative value in all three neutrality tests. 
Table 1. Neutrality test for geographic populations.

\begin{tabular}{|c|c|c|c|c|c|c|c|c|c|c|c|}
\hline \multirow[b]{2}{*}{ Statistics } & \multicolumn{10}{|c|}{ S. s. semitorques } & \multirow{2}{*}{$\begin{array}{c}\text { S. s. cinereicapillus } \\
\text { TAIPEI }\end{array}$} \\
\hline & GSWX & SXFP & SCGY & SCYA & SNJ & JXJGS & HNYJ & GZGD & AHJX & FJ & \\
\hline Tajima's $D$ & -0.933 & -1.633 & -0.109 & -0.7064 & -0.996 & -0.694 & -0.591 & -0.691 & -0.986 & -1.199 & -0.894 \\
\hline$P$ & NS & NS & NS & NS & NS & NS & NS & NS & NS & NS & NS \\
\hline Fu's $F s$ & -4.843 & -12.75 & -1.283 & -3.336 & -2.752 & -1.908 & -5.719 & -6.401 & -2.764 & -1.554 & -1.633 \\
\hline$P$ & $<0.01$ & 0.00 & NS & NS & NS & NS & NS & NS & NS & NS & NS \\
\hline Fu and Li's $D$ & -1.313 & -2.803 & -0.109 & -0.640 & -1.270 & -0.798 & -0.765 & -1.360 & -1.370 & -1.199 & -0.894 \\
\hline$P$ & NS & $<0.05$ & NS & NS & NS & NS & $<0.01$ & $<0.01$ & NS & NS & NS \\
\hline
\end{tabular}

Note: Three neutrality test parameters and statistical $\mathrm{p}$ values were calculated by DnaSP 5.0.

AMOVA analysis show explicit divergence between two subspecies of Collared Finchbill (Table 2). We attempted to identify possible intraspecific genetic structure by defining several different ways of groupings in S. s. semitorques. However, AMOVA could not find a pattern with significant variation within any grouping. This indicates that there is no substantial genetic subdivision across subspecies on the mainland of China. Most of the variation is accounted for within-population variation, as could be expected given the large number of singletons. There is no correlation between $F_{s t}$ genetic distance and geographic distance (Mantel test, $\mathrm{Z}=118.0163, r=-0.1863, p=0.9475$ ) in $S$. s. semitorques (Figure 2).

Table 2. AMOVA analyses of Collared Finchbill.

\begin{tabular}{|c|c|c|c|c|}
\hline Group & $\begin{array}{c}\text { Among } \\
\text { groups } \\
\text { (AG) }\end{array}$ & $\begin{array}{c}\text { Among } \\
\text { populations } \\
\text { within } \\
\text { groups(AP) }\end{array}$ & $\begin{array}{c}\text { Within } \\
\text { populations } \\
\text { (WP) }\end{array}$ & Percentage of variation \\
\hline & FCT & FSC & FST & \\
\hline $\begin{array}{r}2 \text { Groups S. s. semitorques (mainland } \\
\text { sites): S. s. cinereicapillus } \\
\text { (TAIPEI) }\end{array}$ & 0.5043 & 0.0098 & 0.5092 & $\begin{array}{c}\text { Among groups:50.44 } \\
\text { Among populations within } \\
\text { group: } 0.49 \\
\text { Within populations: } 49.08\end{array}$ \\
\hline $\begin{array}{c}6 \text { Groups East(AHJX, JSNJ): } \\
\text { West(SCYA, SCGY): Southeast(FJ): } \\
\text { Southwest(GZGD, GXJZS): Central } \\
\text { (JXJGS, HNYJ, HNWG, SNJ): } \\
\text { Northwest(GSWX, SXFP) }\end{array}$ & 0.0029 & 0.0067 & 0.0096 & $\begin{array}{l}\text { Among groups: } 0.29 \\
\text { Among populations within } \\
\text { group: } 0.67 \\
\text { Within populations: } 99.04\end{array}$ \\
\hline
\end{tabular}

Note: For two groups, S. s. semitorques includes populations on mainland and S. s. cinereicapillus includes the population in Taiwan. 
Figure 2. Data plot of the genetic distance $\left(F_{s t}\right) v s$. geographical distance (Log geographical distance in $\mathrm{km}$ ) of the Mainland Spizixos semitorques populations, showing the RMA regression line $\left(R^{2}=0.0167\right)$.

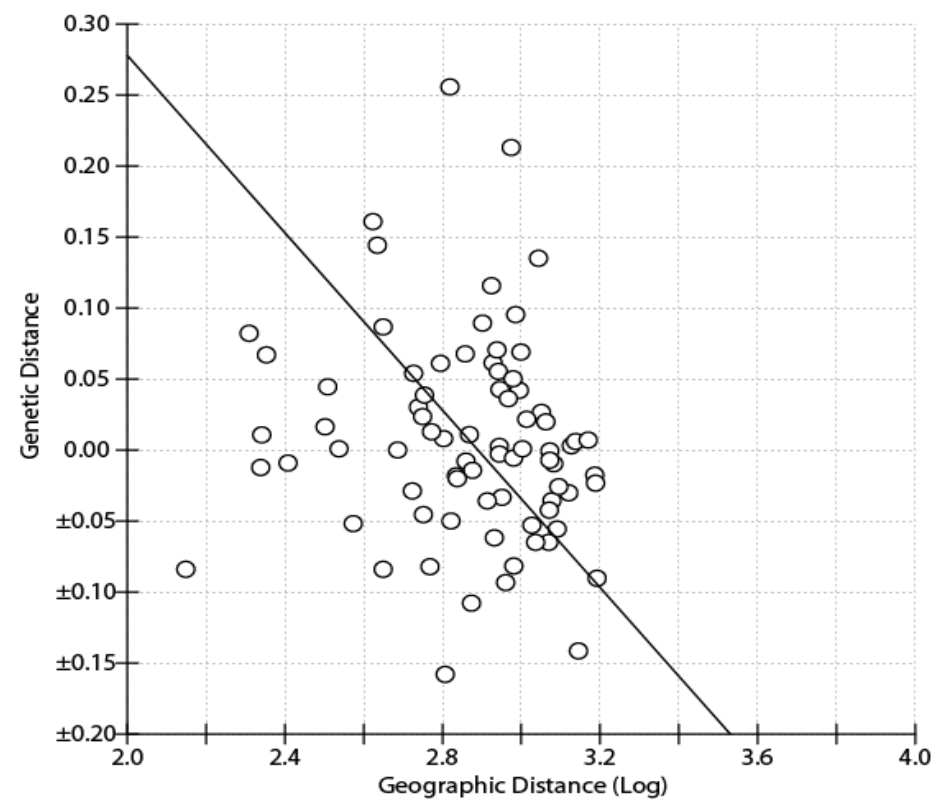

MDIV gave an average of $0.44,0.311$ and 20.39 for TMRCA, $t_{p o p}$ and $\theta$ value respectively. Divergence time between two subspecies of Collared Finchbills was estimated to be about $87 \mathrm{Kyr}$. Meanwhile LAMARC estimated $\theta$ value for eight populations of $S$. s. semitorques. HNYJ population has a $\theta$ value of 0.00806 which was larger than any population around it. ANJX population got relatively lower $\theta$ value of 0.00249 and the remaining populations' results range from 0.00333 to 0.00524. LAMARC also detected extensive gene flows among geographic populations of S. s. semitorques (Figure 3).

Figure 3. Effective population size and gene flow among populations estimated by LAMARC.

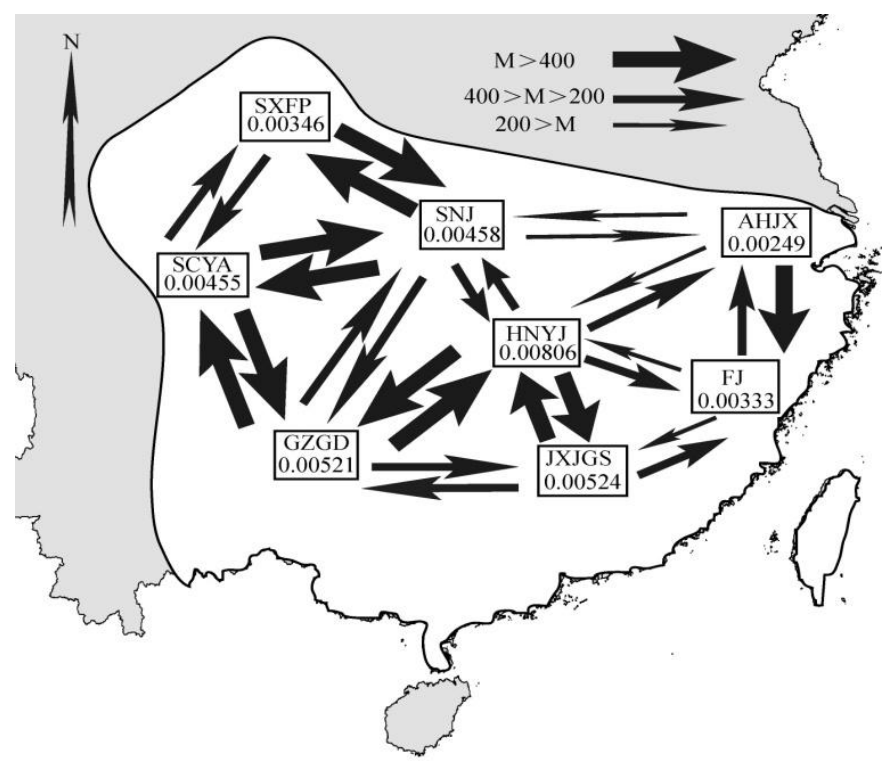




\subsection{Discussion}

Both local populations and the whole species of Collared Finchbill are characterized by high haplotype diversity and low nucleotide diversity. MtDNA markers detect an indistinctive genetic structure. These findings imply that the present populations of the S. semitorques seemed not to be affected by LGM and not segregated by topological complexity of South China. The results provide evidence of undiversified population structure.

Genetic variation is likely homogeneously distributed among populations on mainland China. The result suggested an undistinguished genetic structure of $S$. s. semitorques haplotypes bear strong signals of: an irregular haplotypes network, high haplotype diversity and low nucleotide diversity, and no significant negative value of Tajima' $D$ detected for all geographic populations.

Results of AMOVA also show that there is no population subdivision on a regional scale, and only a small amount of variation could be attributed to groups $(\sim 1.5 \%)$. The majority of the variations $(99 \%$ variation is found within populations, Table 2) were found within S. s. semitorques populations, possibly as a result of strong gene flows among geographic populations. Mantel Test analyses do not indicate the pattern of isolation by distance among all sampling sites of S. s. semitorques in South China. This indicates there is no geographic barrier to segregate $S$. s. semitorques.

A pattern of high haplotype diversity and low nucleotide diversity is noted, which could be attributed to population expansion [19]. Given the harsh conditions during the Quaternary, there might have been numerous bottleneck events decreasing population size and genetic variability until such time as conditions became more favorable.

\section{Demographic History}

Although European and Asian continents cover similar latitude of Northern Hemisphere, they experienced different glacial histories [2,3,20]. Some compared phylogeographical researches indicated that Asian and European populations of the same species have obviously different genetic differentiation pattern [21-23]. This could reflect a different mechanism of species-specific responses to the glaciations. For example, many European species experienced post-glacial expansion due to the glaciations in the Quaternary, and expansion time roughly dated back to the retreat of the Last Maximum Glaciation (LGM) [2,3,20]. However, for many species distributes in Asia, their phylogeographic structures seemed not to be substantially affected by the LGM. Some extant species kept a stable population size during that time, but did not obviously expand with ice retreat after the LGM [14]. Three previous studies revealed intraspecific divergence and demographic history of some avian species in south China as a result of the Pleistocene climate change [14,16,17]. Mitochondrial data of Leucodioptron canorum canorum indicated the populations kept growing since penultimate ice age. This means complex topology of South China provided suitable habitats for L. c. canorum. Another example is Alcippe morrisonia, which widely distributes in South China and its ancestor dated back to 8 Myr. Geographical populations of A. morrisonia also kept stable or grew slightly during the LGM. Bambusicola thoracica thoracica showed a geographical structure among populations with little gene flow. 
Unlike Alcippe morrisonia (Aves: Timaliidae), which is widespread in southern China and often flocks in the medium and understory of tropical rain forests and subtropical broadleaf evergreen forests [24,25], S. semitorques usually inhabits the canopy and edge of shrub land and has a larger body size [24] which might enable $S$. semitorques to have vagility and adaptability superior to A. morrisonia. The phylogeographical structure of A. morrisonia showed a deep lineage divergence while S. semitorques only have a shallow differentiation among geographical populations. Palynological and palaeoclimatic data suggest that the vegetation in East Asia in $35 \mathrm{Kyr}$ ago similar to observed today might be ascribed to high precipitation, especially at middle or low latitudes [26-28]. The present results imply that during the cyclical oscillations of ice age, S. semitorques might stay relatively stable in certain areas of southern China.

East Asia has experienced several cyclical changes due to the sea level rising and falling. These sea level fluctuations started in the Early Miocene (24 Myr BP), and became more frequent after $10 \mathrm{Myr}$, and particularly during the Quaternary. Such changes of sea level led to occasional connection/disconnection between mainland and Taiwan. Divergence time of the two subspecies dated back to $87 \mathrm{Kyr}$ BP while the TMRCA was estimated to 0.44 Myr BP. This result implied that the rising sea level did not effectively block the two subspecies for a long time until one of the warmest interglacial marine isotope stage 5 (MIS 5:130-74 Kyr) [29]. The sea level was even higher at that time than it presently is [30]; so it is probably that the Taiwan Strait virtually blocked gene flow between two subspecies of $S$. semitorques from then on.

\section{Materials and Methods}

\subsection{Sample Collection, DNA Extraction, Amplification and Sequencing}

A total of 120 samples of Collared Finchbill were collected from 14 localities from 2003 to 2009, covering most of its distribution range in southern China (Table 3 and Figure 4). Liver/muscle samples were stored in $100 \%$ ethanol immediately after removal. Total genomic DNA was extracted from tissue samples using the DNeasy Blood and Tissue Kit (QIAGEN) following the manufacturer's instructions. A partial cytochrome b (Cytb) gene of 977 (base pairs, bp) was amplified with the primer pair OSCL1 and $\mathrm{OSCH} 2$ [31]. The thermocycling program consisted of an initial denaturation at $94{ }^{\circ} \mathrm{C}$ for $5 \mathrm{~min}$, followed by 40 cycles of $94{ }^{\circ} \mathrm{C}$ for $40 \mathrm{~s}, 53{ }^{\circ} \mathrm{C}$ for $40 \mathrm{~s}$ and $72{ }^{\circ} \mathrm{C}$ for $40 \mathrm{~s}$, plus a final extension at $72{ }^{\circ} \mathrm{C}$ for $5 \mathrm{~min}$. We used the primers L437 and H1248 [32] to amplify a fragment of $1165 \mathrm{bp}$ from the central D-loop region to the end of the tRNA-Glu gene, including tRNA-Pro and ND6. The PCR thermal profile started with $94{ }^{\circ} \mathrm{C}$ for $3 \mathrm{~min}$ followed by 30 cycles of: $94{ }^{\circ} \mathrm{C}$ for $30 \mathrm{~s}, 55^{\circ} \mathrm{C}$ for $30 \mathrm{~s}$, and $72{ }^{\circ} \mathrm{C}$ for $30 \mathrm{~s}$. Sequencing using the $\mathrm{H} 1248$ primer was problematic, so a full sequence was obtained using two forward primers (16042: 5'-GTCACCAACTCCCAAAGC-3' and 16520: 5'-ACCCAAAGCAAAACATAAACC-3') under designed using Primer Premier 5.0 (Premier Biosoft International, Palo Alto, CA, USA). All individuals were sequenced in both directions (ABI377). The sequences were deposited to GenBank (cytb: JF509464-509583 and D-loop to tRNA-Glu: JF509584-509703). 
Table 3. Sampling information for Collared Finchbill.

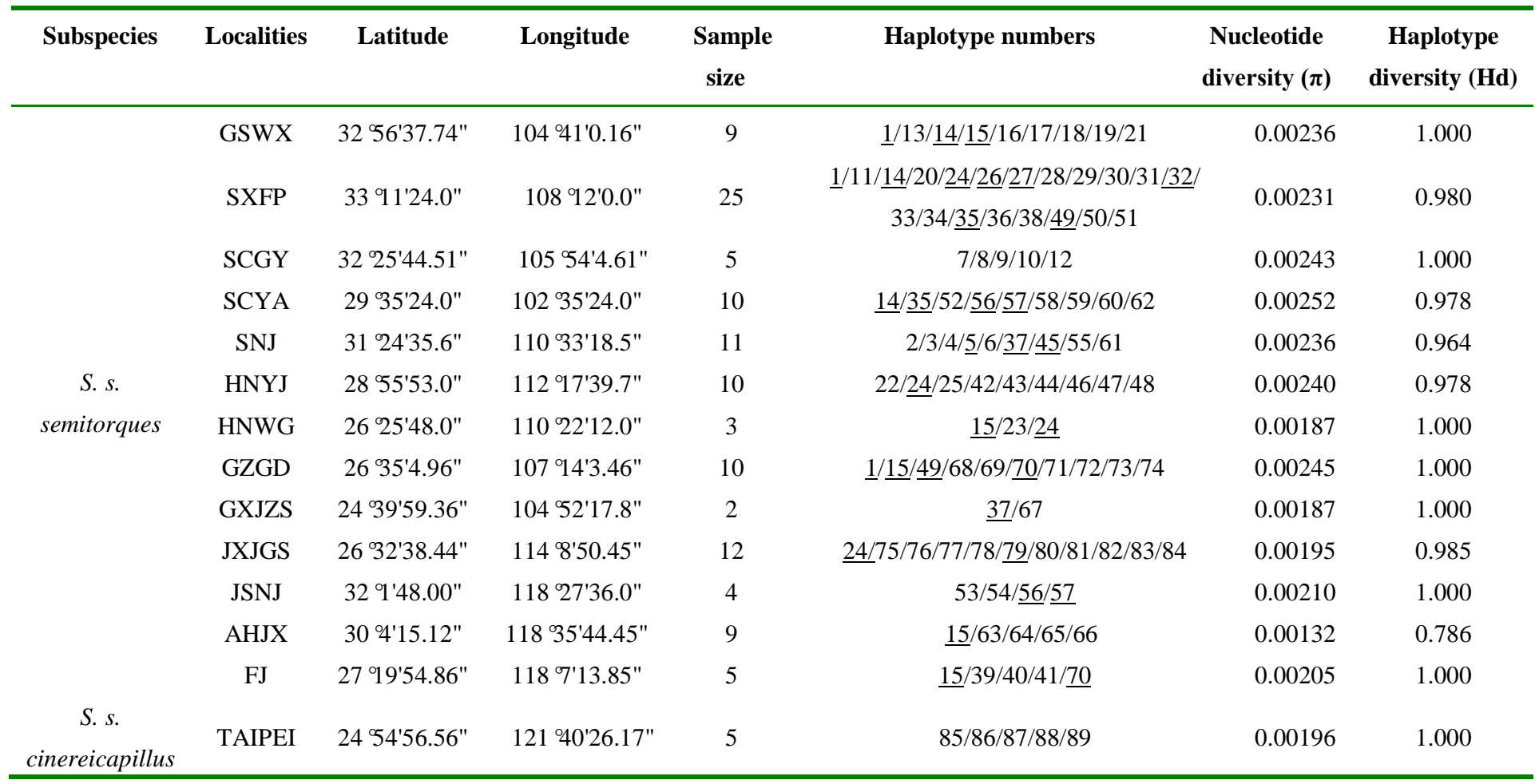

Note: Haplotype numbers are also used in network analysis and underlines denote shared haplotype.

Figure 4. Sampling sites of $S$. s. semitorques: GSWX SXNS SCGY SCYA SNJ GZGD HNYJ JSNJ AHJX GXJZS JXJGS HNWG FJ; S. s. cinereicapillus: TAIPEI. Circles' size is proportional to amount of each sampling site.

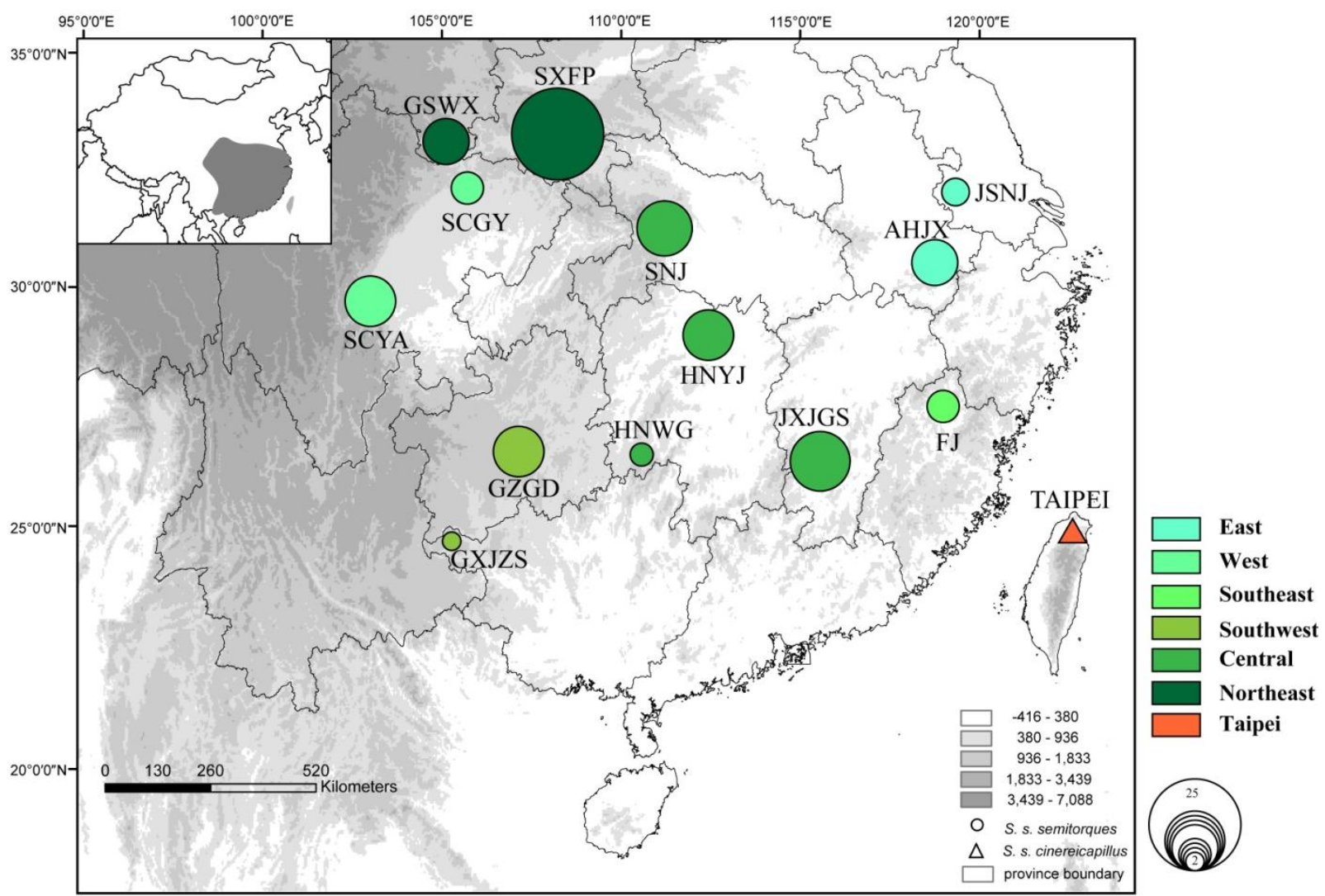




\subsection{Sequence Analysis}

Fourteen sampling sites were identified for $S$. s. semitorques and one location for S. s. cinereicapillus (showed in Table 1). Sequences were aligned and edited using BioEdit 7.0 [33] and refined manually. DnaSP 5.0 [34] was used to calculate the number of segregating sites, haplotypes, haplotype diversity (h) [35], nucleotide diversity [36]. Genetic distance was computed using Arlequin 3.11 [37]. Tajima's $D$ [38] was used to examine the selective neutrality of mitochondrial fragments. Two additional neutrality tests, Fu and Li's $D$ [39] and Fu's $F_{\mathrm{S}}$ [40] were used to detect departures from the mutation-drift equilibrium. $F_{S}$ value tends to be negative if there is a significant excess of rare haplotypes, thus is often taken as evidence of recent demographic expansions or population bottlenecks [40]. All three tests were implemented in DnaSP 5.0 [34].

We used the combined sequences to reconstruct median-joining (MJ) network by program Network4.6 [41]. Mantel tests for isolation by distance (IBD) were performed using IBDWS [42]

MDIV [43] was employed to estimate divergence time and migration rate between two subspecies. Aligned sequence data from sample sites were used to estimate the parameters $H\left(=2 N_{e} l\right)$, $M\left(=N_{e} m=\right.$ number of migrants between populations per generation), and $T$ (the divergence time between populations, where 1 time unit $=N_{\mathrm{e}}$ generations). Each analysis used an infinite-site model and 3000,000 generations of Markov chain Monte Carlo run and the first 500,000 generations was discarded as burn-in. Priors of maximum of $\mathrm{M}$ and $\mathrm{T}$ were set to 5 and 10 respectively. The divergence time between subspecies was estimated using the Formula $t_{\text {divergence time }}=T_{\text {pop }} \times($ Theta $/ 2 \mu \mathrm{k})$.

Molecular clock is widely used for the liable of sequence information. But the constancy of clocks have been controversial, particularly if they clash with estimates taken from more traditional sources such as the fossil record. Songbirds (Passeriformes) have a very limited fossil record in spite of making up more than one-half of the world's 10,000 living species of birds. There has been no fossil reported for Pycnonotidae birds. Different species have different molecular clock due to life cycles and metabolic rates. So for a specific species, a useful clock should be close to calibrated relatives. We used conventional 2\% [44-46] molecular clock as mutation rate and 1.7 years [47] as generation time for Collared Finchbill.

We estimated effective population size $(\Theta)$ and migration rate $(M)$ in the assumption of both populations and migration are at equilibrium with the MCMC chain approach implemented in the program LAMARC 2.1.3 [48]. All analyses used a GTR model of evolution suggested by Model Test 3.7 [49]. Two simultaneous searches with heating scheme were run 10,000,000 steps with an initial burn-in of 1,000,000 steps. LAMARC assumed that a population has been growing at the same exponential rate for a long period of time. Therefore, the ability to detect population growth depends on the amount of time a population experienced growth. Positive values of $\mathrm{g}$ indicated a growing population, and negative values indicated a shrinking population from past to present. The maximum probability estimates (MPE) for population under growth is above zero on average. As g value tended to be inflated, 95\% CI of $\mathrm{g}$ including zero suggested undistinguished deviation from constant population size. Analyses were repeated three times with different random number seeds to assess consistency. The population growth or decline was significant if the $95 \%$ confidence interval of $\mathrm{g}$ did not include zero. The posterior probability densities and ESSs for these estimated population parameters were calculated in Tracer 1.5 [50]. 


\section{Conclusions}

Our study showed undistinguished genetic structure among geographical populations of S. semitorques. Approximate random gene flow indicated there might be no distinctive geographic barriers for this species in south China during late Pleistocene, which differs from the other three species of previous studies. Shallow differentiation due to considerable gene flow and lack of barriers might lead to high haplotype diversity and relative low nucleotide diversity. The mtDNA data showed a short evolutionary history of $S$. semitorques and undistinguished effects of the LGM on its historical demography.

\section{Acknowledgements}

Many thanks to Olivier François for inviting us to contribute a paper for consideration and possible publication in a special issue on "Advances in Molecular Ecology". We thank Ornithological Research Group colleagues for their help with sample collection. This study was supported by the National Science Fund for Distinguished Young Scientists (No. 30925008), Major International (Regional) Joint Research Project (No: 31010103901) and CAS INFO-115-D02, NSFC (30870270, 30670276) to FM Lei, and by a NSFC program grant (J0930004) to Bin Gao.

\section{References}

1. Avise, J. Phylogeography: The History and Formation of Species; Harvard University Press: London, UK, 2000; pp 145-208.

2. Hewitt, G. The genetic legacy of the Quaternary ice ages. Nature 2000, 405, 907-913.

3. Hewitt, G. Genetic consequences of climatic oscillations in the Quaternary. Phil. Trans. Roy. Soc. London B 2004, 359, 183-195

4. Taberlet, P.; Fumagalli, L.; Wust-Saucy, A.G.; Cosson, J.F. Comparative phylogeography and postglacial colonization routes in Europe. Mol. Ecol. 1998, 7, 453-464.

5. Lessa, E.P.; Cook, J.A.; Patton, J.L. Genetic footprints of demographic expansion in North America, but not Amazonia, during the Late Quaternary. Proc. Nat. Acad. Sci. USA 2003, 100, 10331-10334.

6. Zhang, Y.; Ge, S. Molecular evolution study in China: Progress and future promise. Phil. Trans. Roy. Soc. London B 2007, 362, 973-986.

7. Qiu, Y.X.; Fu, C.X.; Comes, H.P. Plant molecular phylogeography in China and adjacent regions: Tracing the genetic imprints of Quaternary climate and environmental change in the world's most diverse temperate flora. Mol. Phylogenet. Evol. 2011, 59, 225-244.

8. Soltis, D.E.; Morris, A.B.; McLachlan, J.S.; Manos, P.S.; Soltis, P.S. Comparative phylogeography of unglaciated eastern North America. Mol. Ecol. 2006, 15, 4261-4293.

9. Shi, Y. Quaternary glaciation in China. Quatern. Sci. Rev. 1986, 5, 503-507.

10. Liu, K. Quaternary history of the temperate forests of China. Quatern. Sci. Rev. 1988, 7, 1-20.

11. Weaver, A.; Eby, M.; Fanning, A.; Wiebe, E. Simulated influence of carbon dioxide, orbital forcing and ice sheets on the climate of the last glacial maximum. Nature 1998, 394, 847-853. 
12. Pinot, S.; Ramstein, G.; Harrison, S.; Prentice, I.; Guiot, J.; Stute, M.; Joussaume, S. Tropical paleoclimates at the last glacial maximum: comparison of Paleoclimate Modeling Intercomparison Project (PMIP) simulations and paleodata. Clim. Dynam. 1999, 15, 857-874.

13. Ju, L.; Wang, H.; Jiang, D. Simulation of the last glacial maximum climate over East Asia with a regional climate model nested in a general circulation model. Palaeogeogr. Palaeoclimatol. 2007, 248, 376-390.

14. Li, S.; Yeung, C. Sailing through the Late Pleistocene: unusual historical demography of an East Asian endemic, the Chinese Hwamei (Leucodioptron canorum canorum), during the last glacial period. Mol. Ecol. 2009, 18, 622-633.

15. Qian, H.; Ricklefs, R.E. Large-scale processes and the Asian bias in species diversity of temperate plants. Nature 2000, 407, 180-182.

16. Song, G.; Qu, Y.; Yin, Z.; Li, S.; Liu, N.; Lei, F. Phylogeography of the Alcippe morrisonia (Aves: Timaliidae): Long population history beyond late Pleistocene glaciations. BMC Evol. Biol. 2009, 9, 143.

17. Huang, Z.; Liu, N.; Liang, W.; Zhang, Y.; Liao, X.; Ruan, L.; Yang, Z. Phylogeography of Chinese bamboo partridge, Bambusicola thoracica thoracica (Aves: Galliformes) in south China: Inference from mitochondrial DNA control-region sequences. Mol. Phylogenet. Evol. 2010, 56, 273-280.

18. MacKinnon, J.; Phillipps, K.; He, F. A Field Guide to the Birds of China; Oxford University Press: New York, NY, USA, 2000; pp 362-363.

19. Grant, W.; Bowen, B. Shallow population histories in deep evolutionary lineages of marine fishes: insights from sardines and anchovies and lessons for conservation. J. Hered. 1998, 89, 415-427.

20. Hewitt, G. Some genetic consequences of ice ages, and their role, in divergence and speciation. Biol. J. Linn. Soc. 1996, 58, 247-276.

21. Kryukov, A.; Iwasa, M.; Kakizawa, R.; Suzuki, H.; Pinsker, W.; Haring, E. Synchronic east-west divergence in azure-winged magpies (Cyanopica cyanus) and magpies (Pica pica)*. J. Zool. Syst. Evol. Res. 2004, 42, 342-351.

22. Zink, R.M.; Drovetski, S.V.; Questiau, S.; Fadeev, I.V.; Nesterov, E.V.; Westberg, M.C.; Rohwer, S. Recent evolutionary history of the bluethroat (Luscinia svecica) across Eurasia. Mol. Ecol. 2003, 12, 3069-3075.

23. Pavlova, A.; Zink, R.M.; Drovetski, S.V.; Red'kin, Y.; Rohwer, S. Phylogeographic patterns in Motacilla flava and Motacilla citreola: species limits and population history. Auk 2003, 120, 744-758.

24. Zou, F.; Chen, G. A study of understory bird communities in tropical mountain rain forest of Jianfengling, Hainan Island, China. Acta Ecol. Sinica 2004, 24, 510-516.

25. Taiwanica, A.Z. Diet analysis of the gray-cheeked Fulvetta (Alcippe morrisonia) at Fushan Experimental Forest in Taiwan. Acta Zool. Taiwan 1998, 9, 59-66.

26. Yuan, D.; Cheng, H.; Edwards, R.; Dykoski, C.; Kelly, M.; Zhang, M.; Qing, J.; Lin, Y.; Wu, J. Timing, duration, and transitions of the last interglacial Asian monsoon. Science 2004, 304, $575-578$. 
27. Kelly, M.; Edwards, R.; Cheng, H.; Yuan, D.; Cai, Y.; Zhang, M.; Lin, Y.; An, Z. High resolution characterization the Asian Monsoon between 146,000 and 99,000 years BP from Dongge Cave, China and global correlation of events surrounding Termination II. Palaeogeogr. Palaeoclimatol. 2006, 236, 20-38.

28. Yu, G.; Gui, F.; Shi, Y.; Zheng, Y. Late marine isotope stage 3 palaeoclimate for East Asia: A data-model comparison. Palaeogeogr. Palaeoclimatol. 2007, 250, 167-183.

29. Zhao, B.; Wang, Z.; Chen, J.; Chen, Z. Marine sediment records and relative sea level change during late Pleistocene in the Changjiang delta area and adjacent continental shelf. Quatern. Int. 2008, 186, 164-172.

30. Hearty, P.J.; Hollin, J.T.; Neumann, A.C.; O’Leary, M.J.; McCulloch, M. Global sea-level fluctuations during the Last Interglaciation (MIS 5e). Quatern. Sci. Rev. 2007, 26, 2090-2112.

31. Qu, Y.; Lei, F. Comparative phylogeography of two endemic birds of the Tibetan plateau, the white-rumped snow finch (Onychostruthus taczanowskii) and the Hume's ground tit (Pseudopodoces humilis). Mol. Phylogenet. Evol. 2009, 51, 312-326.

32. Tarr, C. Primers for amplification and determination of mitochondrial control-region sequences in oscine passerines. Mol. Ecol. 1995, 4, 527-530.

33. Hall, T. BioEdit: A User-Friendly Biological Sequence Alignment Editor and Analysis Program for Windows 95/98/NT. Nucleic Acids Symp. 1999, 41. 95-98.

34. Librado, P.; Rozas, J. DnaSP version 5.0: A software for comprehensive analysis of DNA polymorphism data. Bioinformatics 2009, 25, 1451-1452.

35. Nei, M. Molecular Evolutionary Genetics; Columbia Universiy Press: New York, NY, USA, 1987.

36. Nei, M.; Tajima, F. DNA polymorphism detectable by restriction endonucleases. Genetics 1981, 97, 145-163.

37. Excoffier, L.; Laval, G.; Schneider, S. Arlequin (version 3.0): An integrated software package for population genetics data analysis. Evol. Bioinform. 2005, 1, 47-50.

38. Tajima, F. Statistical method for testing the neutral mutation hypothesis by DNA polymorphism. Genetics 1989, 123, 585-595.

39. Fu, Y.; Li, W. Statistical tests of neutrality of mutations. Genetics 1993, 133, 693-709.

40. Fu, Y.X. Statistical tests of neutrality of mutations against population growth, hitchhiking and background selection. Genetics 1997, 147, 915-925.

41. Bandelt, H.; Forster, P.; Röhl, A. Median-joining networks for inferring intraspecific phylogenies. Mol. Biol. Evol. 1999, 16, 37-48.

42. Jensen, J.; Bohonak, A.; Kelley, S. Isolation by distance, web service. BMC Genet. 2005, 6, 13.

43. Nielsen, R.; Wakeley, J. Distinguishing migration from isolation: A Markov chain Monte Carlo approach. Genetics 2001, 158, 885-896.

44. Weir, J.; Schluter, D. Calibrating the avian molecular clock. Mol. Ecol. 2008, 17, 2321-2328.

45. Weir, J.T. Divergent timing and patterns of species accumulation in lowland and highland neotropical birds. Evolution 2006, 60, 842-855.

46. Lovette, I.J. Mitochondrial dating and mixed support for the " $2 \%$ rule" in birds. Auk 2004, 121, $1-6$. 
47. Sæther, B.E.; Lande, R.; Engen, S.; Weimerskirch, H.; Lillegard, M.; Altwegg, R.; Becker, P.H.; Bregnballe, T.; Brommer, J.E.; McCleery, R.H.; Merilä, J.; Nyholm, E.; Rendell, W.; Tryjanowski, P. Generation time and temporal scaling of bird population dynamics. Nature 2005, 436, 99-102.

48. Kuhner, M. LAMARC 2.0: Maximum likelihood and Bayesian estimation of population parameters. Bioinformatics 2006, 22, 768-770.

49. Posada, D.C.; Crandall, K.A. MODELTEST: Testing the model of DNA substitution. Bioinformatics 1998, 14, 817-818.

50. Rambaut, A.; Drummond, A.J. Tracer v1.5, 2007. Available online: http://beast.bio.ed.ac.uk/Tracer (accessed on 29 March 2011).

(C) 2011 by the authors; licensee MDPI, Basel, Switzerland. This article is an open access article distributed under the terms and conditions of the Creative Commons Attribution license (http://creativecommons.org/licenses/by/3.0/). 